\title{
Impact of Green Product Knowledge and Perception on Green Purchase Intention: Moderating Role of Price Consciousness
}

\author{
Dr. ALI HAIDER \\ Lecturer, Faculty of Management Sciences, International Islamic University Islamabad. \\ Email: eelihaider@iiu.edu.pk \\ Dr. MALIK MUHAMMAD FAISAL \\ Assistant Registrar, University Institute of Management Sciences, \\ Pir Mehr Ali Shah Arid Agriculture University, Rawalpindi. \\ Email: faisal@uaar.edu.pk
}

FIZZA ASIF

Ph.D Scholar, Faculty of Management Sciences, Capital University of Science and Technology Islamabad.

Email: fizzaasif204@gmail.com

\begin{abstract}
Green products are rapidly moving from niche markets to large market segments and number of consumers purchasing green products are rapidly penetrating mainstream markets (Roberts, 1996). As majority of the consumers are concerned about environment, green markets are developing rapidly and quickly (Peateie and Crane, 2005). These green markets have created essence of doing green marketing. Price is one of such factors that may prevent a green consumer to buy an eco-friendly product (Bonini and Oppenheim, 2008). Tanner and Wölfing Kast, 2003 also confirms this relationship between buying intentions of consumers and price of green products.Also, environmental consciousness among customers is increasing making them more concerned about green and responsible purchasing of food. By analyzing this by using theory of reasoned actions, green purchase intentions is affected differently by different and type of prices. Data collected from a sample of 400 consumers while, structured questionnaires were used to gather primary data from consumers. For hypothesis testing process macro was used. CFA was run by using AMOS. There have been discussed results alongwith recommendations and future directions at the end.
\end{abstract}

Keywords: Consumer Product Knowledge, Perceived Quality, Perceived Saving, Consumer Green Attitude, Green Purchase Intention, Price Consciousness.

\section{Introduction}

Environmental consciousness among consumers has been significantly increasing for the last two decades. In the current era, the consumers are more inclined towards purchasing environmental friendly products rather than the products which are not environment friendly. Apart from this, consumers are also becoming price-conscious at the same time as different tools of price promotions affect their behavior differently. However, consumers prefer to purchase green products over other options (Yin et al., 2010) because their concern to environment is stronger than their concern for price (Cerri, Testa and Rizzi, 2018). This preference of buying green products have become the essence of current times due to significant positive impact of green products on public health and ecology (Cerri, Testa and Rizzi, 2018). 
As far as consumers' behavior and attitude are concerned, various factors influence them and especially in case of environment friendly products. According to the study of Yin et al., (2010), these factors comprised but these are not confined to information, experience and knowledge. These three major factors have a significant impact on consumers' buying behavior. As experience, knowledge, and information is related to demographics, there may be a significant variation among consumer segments regarding their behavior towards environment friendly products as per their ages, genders, and income levels (Magnusson et al., 2001).

The above discussion guide that there is a major gap between green purchase intentions and consumer green attitude towards green products (Ha and Janda, 2012; Kilbourne and Pickett, 2008). Price is one of these factors that may prevent a green consumer to buy an eco-friendly product (Bonini and Oppenheim, 2008). On the contrary, there are a number of factors which affect the responsiveness of an environment friendly customer towards a product or service. Tanner and Wölfing Kast, (2003) have also confirmed this relationship between buying intentions of consumers and price of green products. Price perceptions and green purchase attitude are considered as significant factors while discussing the concept of prices in relation The primary objective of this research is to analyze the impact of consumer product knowledge, perceived saving and perceived quality on consumer green purchase intention while using environment friendly products and services. By analyzing the relationship among price consciousness, this study will not only fill a gap in literature but also help the marketer to design strategies particularly regarding pricing plans.

\section{Problem Statement}

There are several reasons for which consumers may opt for eco-friendly products and services while making several compromises on product quality and/or price. The consumers with such green attitude are aware about the notion that usage of green products and/or services preserve and save environment as well as their health. Therefore, they are willing to pay higher prices and compromise on product quality in case of eco-friendly products and/or services when green products compared to less/non eco-friendly products and/or services.

Apart from increasing evidence that eco-friendliness is increasing among consumers, there is still a research gap regarding the relationship between green attitude and purchase intentions of responsible consumers. As discussed earlier, degree of greenness varies depending upon different factors such as price that may impact the purchase decision making of consumers. This gap is further increased in case of developing nations when there is not enough evidence that consumers in developing nations like Pakistan is sensitive to eco-friendly products or services

\section{Problem Identification/Rationale of the Study}

The researcher critically analyzed the research gap available in the literature to bridge that gap. This study explains the moderating effects of price consciousness on the relationship between consumers' green attitude and consumers' green purchase intentions by getting support from the 'Theory of Planned Behavior' (TPB). Until now, none of earlier studies has explored the price consciousness as moderating effect a moderating variable in the area of eco-friendly purchasing behavior, particularly from the perspective of Green dairy products. Hence, this study has accurately identified research problem in the current area being addressed by this study.

\section{Research Questions}

1. Does the consumer product knowledge affect consumer green attitude?

2. Does the consumer perception affect consumer green attitude? 
3. Does the consumer green attitude mediate the relationship of determinants of consumer green attitude and green purchase intention?

4. Does the price consciousness moderate the relationship of consumer green attitude and consumer green purchase intention?

\section{Review of Literature}

In green marketing, green attitude solely depends upon attitudes of consumers regarding ecology. Environmental attitude enables an individual to recognize his/her duties and responsibilities to preserve the environment. There are some contradictions in research regarding the relationship between attitude of individuals towards environment and their resultant buying behavior (Kotchen and Reiling, 2000). So, organizations have to clearly recognize such recent trends in consumer behavior regarding environment. This will enable businesses to craft green marketing strategies for their consumers. In green marketing, environmental consciousness among consumers is further increased by developing environmentally sustainable (green) products and services. Such products and services will act as a 'tool of environmental preservation'.

A consumer with green attitude will always focus on buying sustainable, ethical, and environmental friendly products that do not harm the environment (Gilg et al., 2005). In the studies of (Chang, 2012, Bhattacharya, 2011 and Boztepe, 2016) it was found that green consumers were more likely to give up bad habits which may harm the environment and they are more likely to change their behavior by purchasing green products even by compromising on price, quality, and branding of the product. Examples of green purchasing or green consumerism include recycling, minimizing energy consumption, buying hybrid cars, or green food products (Bonini and Oppenheim, 2008).

Knowledge of the consumers impact their environmental behavior in different ways. First of all, knowledge is taken as a personal resource by an individual while making environmental and personal responsibility decisions (Bhattacharya, 2011). Moreover, knowledge also enable a person to apply behavioral control resulting in ability and motivation to act in a certain situation to execute environment friendly behavior (Carrigan and De Pelsmacker, 2009). Hence, it can be concluded that knowledge about environmental issues motivates a person to adopt an environmentally responsible behavior.

The consumers with high price conscious tend to search for discounts and relative lower prices (Alford and Biswas, 2002) and sometimes they may also ignore the quality of the products with the intention save costs (Cuno, 2008). Price conscious customers are more likely to consume their resources and efforts in searching a low-cost option relative to quality conscious customers because they are sophisticated and less brand conscious than quality conscious customers (Milfont and Sibley, 2012). It means that they conducted high levels of research for price related information to make comparisons among products and services that is a key mediator in their cognitive processing. They are never looking for impulse buying or cues that would reduce their search while they spend more time in price comparisons and analysis (Boztepe, 2016).

It is important to note that price-consciousness when combined with environmental consciousness may result in complicated relationship of degree of greenness, green behavior, and consumer attitudes (Hughner et al., 2007). It means that price conscious green consumer is less likely to make comparisons among environment friendly products and services. In this process, their degree of greenness may reduce as they can opt for less friendly products and services due to lower prices relative to more friendly products and services (Ha and Janda, 2012). Value premium as per Numraktrakul, et al. (2011) is the extra sum paid for item rather than the typical value; this could show purchaser's ability to pay for green item. Moreover, due to their excessive time consumption in price comparisons and cost/benefit analysis, they are less like to demonstrate a green behavior in the long run. Also, price can be key determinant in their green purchase decision making process (Lee Weisstein et al., 2014). 
Generally, it is perceived by a large consumer group that green products have a poor quality. This group of consumers may not be willing to pay premium prices due to their price sensitivity and perceived quality (Milfont and Sibley, 2012). Contrary to this, consumers who are highly responsible to environment may associate 'greenness' of the product with quality. As a result, they may compromise the performance for greenness by considering greenness as a quality indicator. This highlights the role of perceived quality to affect the purchase intentions and behaviors of consumers (Yin, Wu, Du, \& Chen, 2010).

\section{Hypotheses}

H1: Consumer product knowledge has positive and significant effect on consumer green attitude.

$\mathrm{H} 2$ : Consumer green attitude has positive and significant effect on green purchase intention.

H3: Perceived quality has positive and significant effect on consumer green attitude.

H4: Perceived saving has positive and significant effect on consumer green attitude.

H5: Price Consciousness will moderate the relationship of consumer green attitude and green purchase intention.

H6: Consumer green attitude will mediate the relationship of consumer product knowledge and green purchase intention.

H7: Consumer green attitude will mediate the relationship of Perceived quality and green purchase intention.

H8: Consumer green attitude will mediate the relationship of Perceived saving and green purchase intention

\section{Material and Methods}

The basic purpose of this study was to discuss and analyze the impact of product knowledge, perceived quality, and perceived savings on the purchase intentions and behavior of green consumers. For this purpose, focus was on testing the listed hypotheses. This study has followed a pragmatic approach by quantitative research methods. The quantitative tool that I have used for gathering primary data was questionnaire survey that are considered as one of the most effective quantitative social research methods (Cooper and Schindler, 2006).

I have collected data from a sample of 400 general consumers while they were engaged in the study using questionnaire surveys. Structured questionnaires were used to gather primary data from consumers of Twin cities of Punjab (Pakistan). I have handed over the questionnaire that consumer filled it and returned the survey later. After data collection, questionnaire was analyzed using Statistical Package Social Science (SPSS) and AMOS software. I used factor analysis for data validation and analysis. For data reliability, Chronbach's Alpha was utilized. For hypothesis testing, process macro was used and for CFA (confirmatory factor analysis) AMOS was used.

The entire returned questionnaire thoroughly checked and data entered. Data screening was used to check whether the data set was complete. Regression analysis through process macro of Hayes was executed to determine how well determinants of consumer green purchase attitude predict consumer green purchase intention. The final step of the data analysis in this research included the total hypothesized moderation.

Model 1, was run through process macro to check the impact of independent variables on dependent variable in the presence of moderator. Model number 4 was run through process macro of Hayes to check the impact of independent variables on dependent variable in the presence of mediator. Model number 16 was run to check the mediation and moderation on complete model, which were merged in one statistical analysis, whereby model sixteen of Hayes (2013) was selected. 
Reliability Analysis

Table No 1: Reliability Test

\begin{tabular}{|ccc|}
\hline Variable & Cronbach's Alpha & Number of Items \\
\hline PC & 0.846 & 3 \\
CPK & 0.812 & 5 \\
PS & 0.843 & 6 \\
CGA & 0.856 & 7 \\
GPI & 0.908 & 11 \\
PQ & 0.852 & 5 \\
\hline
\end{tabular}

The value of Cronbach's alpha for the scale used to measure was $0.846,0.812,0.843,0.856, .908$, and 0.852 for PC, CPK, PS, CGA, GPI and for PQ respectively. These values show the good reliability result which shows a greater consistency among the questions.

\section{Correlation Analysis}

Table No 2

\begin{tabular}{|lllllllll|}
\hline Variable & Mean & $\begin{array}{l}\text { Std. } \\
\text { Dev. }\end{array}$ & CPK & PC & PS & PQ & CGA & GPI \\
\hline CPK & 2.300 & 0.777 & $(0.81)$ & & & & & \\
PC & 2.482 & 0.775 & $.505^{* *}$ & $(0.64)$ & & & & \\
PS & 2.591 & 0.917 & $.384^{* *}$ & $.539^{* *}$ & $(0.84)$ & & & \\
PQ & 2.295 & 0.854 & $.552^{* *}$ & $.639^{* *}$ & $.569^{* *}$ & $(0.85)$ & & \\
CGA & 2.256 & 0.786 & $.557^{* *}$ & $.532^{* *}$ & $.389^{* *}$ & $.589^{* *}$ & $(0.86)$ & \\
GPI & 2.472 & 0.828 & $.560^{* *}$ & $.673^{* *}$ & $.573^{* *}$ & $.699^{* *}$ & $.567^{* *}$ & $(0.91)$ \\
\hline
\end{tabular}

**. Correlation is significant at the 0.01 level (2-tailed).

*. Correlation is significant at the 0.05 level (2-tailed).

\section{Regression Analysis}

Table No 2: Impact of CPK on GPI with mediating role of CGA

\begin{tabular}{|c|c|c|c|c|c|c|c|c|}
\hline \multirow{3}{*}{ Antecedent } & \multicolumn{8}{|c|}{ Consequent } \\
\hline & \multicolumn{3}{|c|}{ M (CGT) } & & & \multicolumn{3}{|c|}{ Y (GPI) } \\
\hline & $\mathrm{B}$ & SE & \multicolumn{2}{|l|}{$\mathbf{P}$} & & $\mathrm{B}$ & SE & $\mathbf{p}$ \\
\hline $\mathrm{X}(\mathrm{CPK})$ & 0.5636 & .04210 & 0.000 & $\mathrm{a} 2$ & $\mathrm{c}^{\prime}$ & 0.3778 & 0.9496 & 0.000 \\
\hline $\mathrm{M}(\mathrm{CGT})$ & --- & --- & --- & & b1 & 0.3893 & 0.0490 & 0.000 \\
\hline \multirow[t]{5}{*}{ Constant } & 0.9601 & 0.1022 & 0.000 & iM2 & i2 & 0.7242 & 0.1106 & 0.000 \\
\hline & \multirow{2}{*}{\multicolumn{4}{|c|}{$\begin{array}{l}\mathrm{R}^{2}=0.3104 \\
\mathrm{~F}(1,398)=179.1048, \mathrm{p}=.000\end{array}$}} & \multicolumn{3}{|c|}{$\mathrm{R}^{2}=0.4075$} & \\
\hline & & & & & \multicolumn{4}{|c|}{$\mathrm{F}(1,398)=181.7179, \mathrm{p}=.000$} \\
\hline & & & \multirow{2}{*}{\multicolumn{2}{|c|}{ Effect }} & \multirow{2}{*}{\multicolumn{2}{|c|}{ SE (Boot) }} & LLCI & $\overline{\text { ULCI }}$ \\
\hline & & & & & & & $(95 \% \mathrm{C}$ & \\
\hline \multicolumn{2}{|l|}{ TE: CPK-->GPI } & & \multicolumn{2}{|c|}{0.5972} & \multicolumn{2}{|c|}{0.442} & 0.5101 & 0.6843 \\
\hline \multicolumn{2}{|l|}{ DE: CPK-->GPI } & & \multicolumn{2}{|c|}{0.3778} & \multicolumn{2}{|c|}{0.0496} & 0.2802 & 0.4754 \\
\hline \multicolumn{2}{|l|}{ CPK-->CGT-->GPI } & & \multicolumn{2}{|c|}{0.2194} & \multicolumn{2}{|c|}{0.491} & 0.1253 & 0.3160 \\
\hline
\end{tabular}


Table shows the results of mediated regression. There is an increment of $9.71 \%$ after the inclusion of CGT as mediator in the model. Total effect of CPK on GPI is also significant at $b=.5972$ with boot strapped values (0.5101 and 0.6843 excluding zeros) at $95 \%$ confidence interval. Direct and indirect effects are also significant at $95 \%$ confidence interval with effect value of 0.3778 and 0.2194 , with bootstrap values of ( 0.2802 and $0.4754,0.1253$ and 0.3160 excluding zeros) respectively.

Table No 3: Impact of PS on GPI with mediating role of CGA

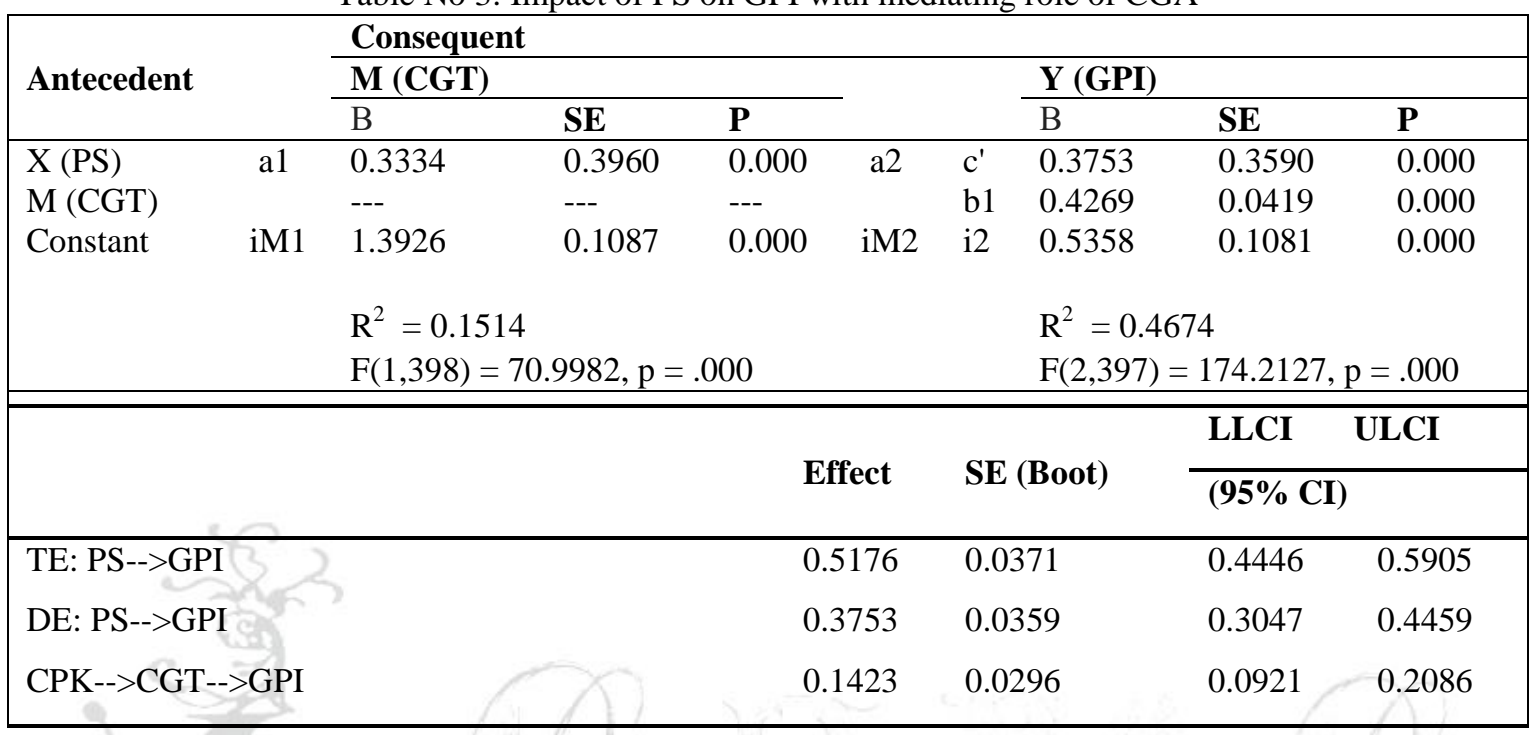

Table shows the results of mediated regression with perceived savings. Initially, the impact of perceived saving was tested on consumer green purchase attitude. There is an increment of $31 \%$ after the inclusion of consumer green purchase attitude as mediator in the model. Total effect of PS on GPI is also significant at $\beta=.5176$ with boot strapped values ( 0.4446 and 0.5905 excluding zeros) at $95 \%$ confidence interval. Direct and indirect effects are also significant at $95 \%$ confidence interval with effect value of 0.3753 and 0.0359 , with bootstrap values of $(0.3047$ and $0.4459,0.0921$ and 0.2086 excluding zeros) respectively.

Table No 4: Impact of PQ on GPI with mediating role of CGA

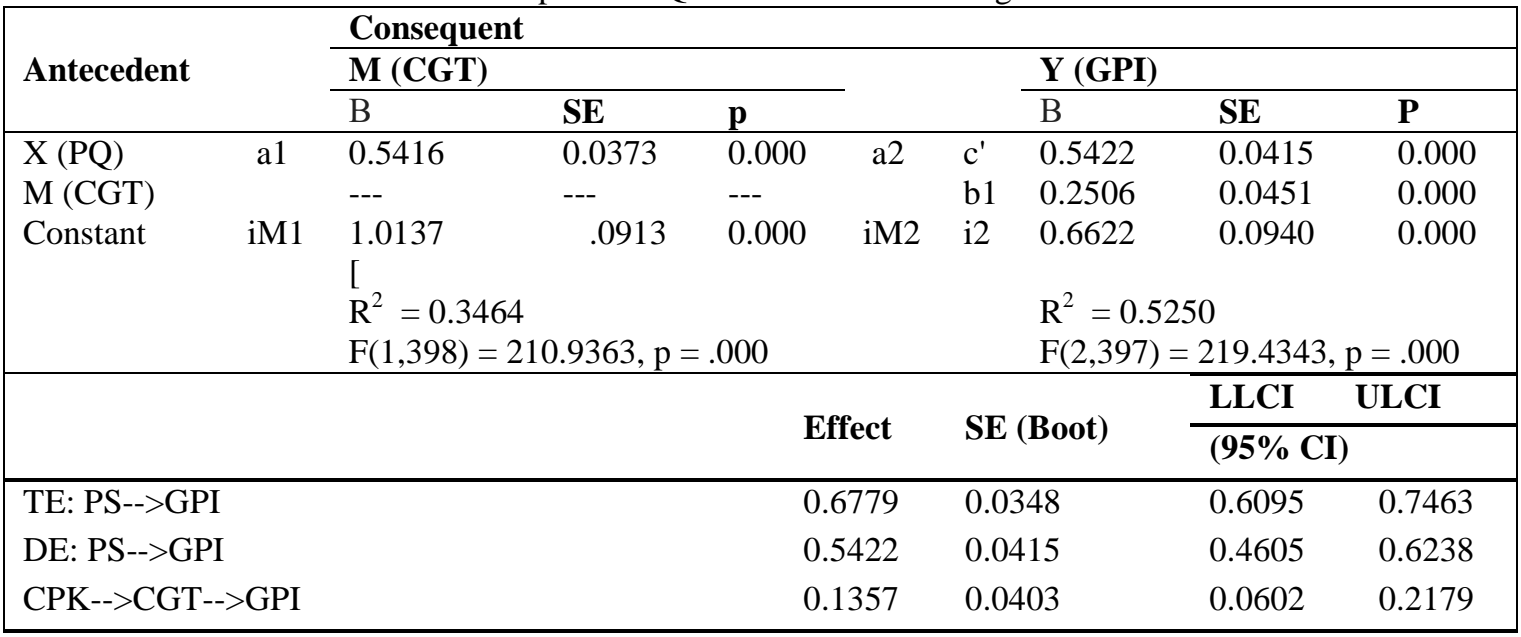

Table shows the results of mediated regression with perceived quality. Initially, the impact of perceived quality was tested on consumer green purchase attitude. 
Table No 5: Impact of CPK on GPI, mediating role of CGA, moderating role of PC

\begin{tabular}{|c|c|c|c|c|c|c|c|c|}
\hline \multirow{3}{*}{ Antecedent } & \multicolumn{8}{|c|}{ Consequent } \\
\hline & \multicolumn{3}{|c|}{ M (CGA) } & & & \multicolumn{3}{|l|}{ Y (GPI) } \\
\hline & $\mathrm{b}$ & $\overline{S E}$ & $\overline{\mathbf{P}}$ & & & $\bar{B}$ & $\overline{\mathbf{S E}}$ & $\overline{\mathbf{P}}$ \\
\hline $\bar{X}(\mathrm{CPK})$ & 0.2794 & 0.0339 & 0.0356 & $\mathrm{a} 2$ & $\mathrm{c}^{\prime}$ & 0.2106 & 0.0356 & 0.1608 \\
\hline $\mathrm{M}(\mathrm{CGA})$ & --- & --- & --- & & b1 & 0.9219 & 0.1487 & 0.0000 \\
\hline $\mathrm{V}(\mathrm{PC})$ & --- & --- & --- & & b2 & 0.1585 & 0.0787 & 0.0447 \\
\hline VxX (CGAxPC) & --- & --- & --- & & b3 & -0.1061 & 0.0327 & 0.0013 \\
\hline Constant & 1.3322 & 0.1169 & 0.0000 & iM2 & i2 & 0.0431 & 0.3598 & 0.9047 \\
\hline & \multicolumn{5}{|c|}{$\begin{array}{l}\mathrm{R}^{2}=0.1462 \\
\mathrm{~F}(1,398)=68.1252 \\
\mathrm{p}=0.000\end{array}$} & \multicolumn{3}{|c|}{$\begin{array}{l}\mathrm{R}^{2}=0.3881 \\
\mathrm{~F}(4,395)=62.6277 \\
\mathrm{p}=.0000\end{array}$} \\
\hline
\end{tabular}

Table No 6: Impact of PQ on GPI, mediating role of CGA, moderating role of PC

\begin{tabular}{|c|c|c|c|c|c|c|c|c|}
\hline \multirow{3}{*}{ Antecedent } & \multicolumn{8}{|c|}{ Consequent } \\
\hline & \multicolumn{3}{|c|}{$\bar{M}$ (CGA) } & & & \multicolumn{3}{|l|}{ Y (GPI) } \\
\hline & $\mathrm{b}$ & SE & $\mathbf{P}$ & & & $\bar{B}$ & $\overline{\mathrm{SE}}$ & $\overline{\mathbf{P}}$ \\
\hline $\mathrm{X}(\mathrm{PQ})$ & 0.0556 & 0.0264 & 0.0356 & $\mathrm{a} 2$ & $\mathrm{c}^{\prime}$ & 0.0374 & 0.0227 & 0.1007 \\
\hline $\mathrm{M}(\mathrm{CGA})$ & --- & & -- & & b1 & 1.0397 & 0.1534 & 0.0000 \\
\hline $\mathrm{V}(\mathrm{PC})$ & --- & & --- & & $\mathrm{b} 2$ & 0.2301 & 0.0812 & 0.0048 \\
\hline $\mathrm{VxX}(\mathrm{CGA}$ & 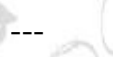 & 17 & --- & & b3 & -0.1061 & 0.0327 & 0.0013 \\
\hline Constant & 2.1092 & 0.0769 & 0.000 & iM2 & i2 & 0.0625 & 0.3789 & 0.8690 \\
\hline & $\begin{array}{l}\mathrm{R}^{2}=0 \\
\mathrm{~F}(1,398 \\
\mathrm{p}=0.0\end{array}$ & 4471 , & & & & $\begin{array}{l}\mathrm{R}^{2}=0.3 \\
\mathrm{~F}(4,395) \\
\mathrm{p}=.000\end{array}$ & 0.2745 , & \\
\hline
\end{tabular}

Table No 7: Impact of PS on GPI, mediating role of CGA, moderating role of PC

\begin{tabular}{|c|c|c|c|c|c|c|c|c|c|}
\hline \multirow{3}{*}{\multicolumn{2}{|c|}{ Antecedent }} & \multicolumn{8}{|c|}{ Consequent } \\
\hline & & \multicolumn{3}{|c|}{ M (CGA) } & & & \multicolumn{3}{|c|}{$\bar{Y}$ (GPI) } \\
\hline & & $\mathrm{b}$ & $\overline{\text { SE }}$ & $\overline{\mathbf{P}}$ & & & B & $\overline{S E}$ & $\overline{\mathbf{P}}$ \\
\hline $\mathrm{X}(\mathrm{PS})$ & $\mathrm{a} 1$ & 0.0441 & 0.0211 & 0.0375 & $\mathrm{a} 2$ & $\mathrm{c}^{\prime}$ & 0.0281 & 0.0182 & 0.1240 \\
\hline $\mathrm{M}(\mathrm{CGA})$ & & --- & --- & --- & & b1 & 1.0205 & 0.1539 & 0.0000 \\
\hline $\mathrm{V}(\mathrm{PC})$ & & --- & --- & --- & & $\mathrm{b} 2$ & 0.2204 & 0.0812 & 0.0069 \\
\hline $\mathrm{VxX}(\mathrm{CG}$ & & --- & --- & --- & & b3 & -0.1023 & 0.0341 & 0.0028 \\
\hline Constant & iM1 & 2.0765 & 0.0913 & 0.000 & iM2 & i2 & 0.0874 & 0.3772 & 0.8168 \\
\hline & & \multicolumn{3}{|c|}{$\begin{array}{l}R^{2}=0.0108 \\
F(1,398)=4.3554 \\
p=0.0375\end{array}$} & & & \multicolumn{3}{|c|}{$\begin{array}{l}\mathrm{R}^{2}=0.3368 \\
\mathrm{~F}(4,395)=50.1506 \\
\mathrm{p}=.0000\end{array}$} \\
\hline
\end{tabular}




\section{Conclusion}

The basic aim to conduct this study is to have better consideration among marketers and consumers to distinguish at different point including those who buy no green food. Many investigations showed that one main consideration that considered being the boundary to green nourishment utilization is its cost, yet given the expansive scope of conceivable components that impacts green sustenance basic leadership, there are others that may considered as boundaries to green sustenance utilization among purchasers. For example, customer item learning on green nourishment and also move made by the advertiser either to advice or to advance, has not achieved the ideal level in empowering manageable utilization with green sustenance. In any case, despite the fact that shoppers has the item learning what added to manageability of condition because of believe of comfort of their present utilization example won't change their recognition towards green sustenance item however great it is.

The survey of the literature proposes that ecologically mindful respondents have a tendency to be guided by estimations of correspondence, supportiveness and compassion for condition. A person's conduct affects nature. While consumers have inspirational conducts towards obtaining items which ar ecological benevolent. Assist environmental knowledge and level of greenness has turned out to be filled in buy choices of numerous people attributable to more noteworthy ecological cordial items mindfulness and uplifting disposition.

Green buy expectation for ecological cordial items is administered by level of greenness for the results of the buy on the environment. Organizations showcasing methodologies underline on the negative effect of items on the earth. Along these lines, firms must put resources into their situating techniques and market correspondence methodologies to change over this antagonism into an open door. It can be inferred that green buy disposition positively affects green buy goal and subsequently green buy conduct. Positive green buy disposition towards ecological neighborly items impact shopper's buy goal to pay the cost for earth benevolent items and at last the buy aim to purchase natural items likewise increments. The more positive buyer saw nature of the green item, and the higher the purchaser green buy state of mind towards natural items, the more positive the ecological inviting buy conduct will be.

\section{Limitations of The Study}

In this research thesis, there are some limitations that deserve of future research. The limitation of this study is that the sample was restricted to a Rawalpindi and Islamabad. Furthermore, this study is crosssectional investigation which is information just gathered at one purpose of time. Shoppers' buy conduct will continually change now and again because of numerous variable impacts. Along these lines, the aftereffect of this finding is unseemly to clarify and mirror the example of customers' buy conduct. In other word, this exploration just ready to portray the example of shoppers' buy conduct at one purpose of time.

\section{Future Research Direction}

Since consumer's perception towards green product has a strong correlation with the purchase intention of green products, therefore it is better to further investigate the details of how the availability of green products may impact the purchase intention. Hopefully this might help marketers with better selling point when promoting these products to the public at large. Consequently, it is very much important if such communication message or educational activities can be initiated at the earlier stage before the consumption behavior becomes habit. Events such as green products fairs and shows should be held and showed among young consumers at their early age before they reach the stage of determining their future identity and self values. I also suggest that longitudinal study is more suitable for future research. 


\section{References}

Alford, B. and L. A. Biswas. 2002. The effects of discount level, price consciousness and sale proneness on consumers' price perception and behavioral intention. J. Bus. Res., 55: 775-783.

Bhattacharya, S. (2011). Consumer attitude towards green marketing in India. IUP Journal of Marketing Management, 10(4).

Bonini, S., \& Oppenheim, J. (2008). Cultivating the green consumer. Stanford Social Innovation Review, 6(4), 56-61.

Carrigan, M., \& De Pelsmacker, P. (2009). Will ethical consumers sustain their values in the global credit crunch?. International Marketing Review, 26(6), 674-687.

Cerri, J., Testa, F., \& Rizzi, F. (2018). The more I care, the less I will listen to you: How information, environmental concern and ethical production influence consumers' attitudes and the purchasing of sustainable products. Journal of Cleaner Production, 175, 343-353.

Cooper, D.R., Schindler, P.S. (2006), Marketing Research, international ed., McGrawHill Irwin, Boston, MA,

Cuno, A. 2008. College students' ethical perceptions on buying counterfeit products. MS. Thesis, Faculty of the Graduate School University of Missouri.

Gilg, A., S. Barrand and N. Ford. 2005. Green consumption or sustainable lifestyles? Identifying the sustainable consumer. Futures, 37(6): 481-504.

Ha, H.Y. and S. Janda. 2012. Predicting consumer intentions to purchase energy-efficient products. J. Consum. Market., 29(7): 461-469.

Hayes, A. F. (2013). Methodology in the social sciences.

Hughner, R. S., P. McDonagh, A. Prothero, C. J. Shultz and J. Stanton. 2007. Who are organic food consumers? A compilation and review of why people purchase organic food. J. Consum. Behav., 6(23): 94-110.

Kilbourne, W., \& Pickett, G. (2008). How materialism affects environmental beliefs, concern, and environmentally responsible behavior. Journal of Business Research, 61(9), 885-893.

Kotchen, M. J. and S. D. Reiling. 2000. Environmental attitudes, motivations and contingent valuation of nonuse values: a case study involving endangered species. Ecol. Eco., 32(1): 93-107.

Lee Weisstein, F., Asgari, M., \& Siew, S. W. (2014). Price presentation effects on green purchase intentions. Journal of Product \& Brand Management, 23(3), 230-239.

Lichtenstein, R. D., N. M. Ridgway and R. G. Netemeyer. 1993. Price Perceptions and Shopping Behavior: A Field Study. J. Marketing Res., 30: 234-245.

Magnusson, M. K., A. Arvola, U. K. Koivisto-Hursti, L. Åbergand P. O. Sjödén. 2001. Attitudes towards organic foods among Swedish consumers. Brit. Food J., 103(3): 209-227.

Milfont, T. L., Sibley, C. G. 2012. The Big Five personality traits and environmental engagement: Associations at the individual and societal level. Journal of Environmental Psychology 32: 187-195.

Numraktrakul, P., A. Ngarmyarn and S. Panichpathom.2012. Factors Affecting Green Housing Purchase. In $17^{\text {th }}$ International Business Research Conference. Toronto, Canada.

Peattie, K., \& Crane, A. (2005). Green marketing: legend, myth, farce or prophesy?. Qualitative market research: an international journal, 8(4), 357-370

Roberts, J. A. 1996. Green consumers in the 90s: profile and implications for advertising, J. Bus. Res., 36(3): 217-232.

Tanner, C., \& Wölfing Kast, S. (2003). Promoting sustainable consumption: Determinants of green purchases by Swiss consumers. Psychology \& Marketing, 20(10), 883-902.

Yin, S., L. Wu, L. Du and M. Chen. 2010. Consumers' purchase intention of organic food in China. J. Sci. Food Agr., 90: 1361-1367 